The utilization of fiber Bragg grating sensors to monitor high performance concrete at elevated temperature

This article has been downloaded from IOPscience. Please scroll down to see the full text article.

2004 Smart Mater. Struct. 13784

(http://iopscience.iop.org/0964-1726/13/4/016)

The Table of Contents and more related content is available

Download details:

IP Address: 140.112.113.225

The article was downloaded on 13/02/2009 at 09:47

Please note that terms and conditions apply. 


\title{
The utilization of fiber Bragg grating sensors to monitor high performance concrete at elevated temperature
}

\author{
Yung Bin Lin ${ }^{1}$, Jenn Chuan Chern ${ }^{1}$, Kuo-Chun Chang ${ }^{1}$, \\ Yin-Wen Chan ${ }^{1}$ and Lon A Wang ${ }^{2}$ \\ ${ }^{1}$ Department of Civil Engineering, National Taiwan University, Taipei 10617, Taiwan \\ ${ }^{2}$ Department of Electrical Engineering and Graduate Institute of Electro-Optical \\ Engineering, National Taiwan University, Taipei 10617, Taiwan \\ E-mail: jcchern@ntu.edu.tw, ciekuo@ntu.edu.tw and lon@ntu.edu.tw
}

Received 22 October 2002, in final form 12 February 2004

Published 1 June 2004

Online at stacks.iop.org/SMS/13/784

doi:10.1088/0964-1726/13/4/016

\begin{abstract}
Embedded optical fiber Bragg grating (FBG) sensors are used to evaluate the properties of high performance concrete (HPC), subjected to high thermal strain. HPC is composed of polypropylene fibers and steel fibers, as additives, in a cylindrical concrete filled steel tube (CFT). A good agreement response between the FBG temperature sensor and a thermocouple was obtained. In addition, experimental results indicate that a CFT behaves differently from unconfined concrete in the center of a specimen, at a furnace temperature of $250^{\circ} \mathrm{C}$ and that polypropylene fibers potentially have a higher capability to restrain spalling than do steel fibers.
\end{abstract}

(Some figures in this article are in colour only in the electronic version)

\section{Introduction}

Concrete filled steel tubes are used to improve load-bearing capacity and stiffness by the combined advantages of steel and concrete. They also have superior fire resistance when compared with conventional steel tubes without concrete inside. However, the strain on concrete at elevated temperatures is hard to measure, since strain gauges fail at high temperatures. In addition, when the material is subjected to fire, it is difficult for these gauges to remain either attached to the surface or embedded in the concrete.

The extent to which high temperature exposure affects the mechanical properties of concrete has been investigated since the 1940s. While the earlier studies used mainly normal-strength concrete (NSC) specimens, studies in recent decades have utilized high-strength concrete (HSC) in the high-heating rate test, generally consisting of both concrete prisms and cylinders of various sizes. The specimens can be made of a combination of concrete mixtures: for example, conventional Portland cement with silica fumes, fly ash or steel fibers added; various coarse aggregates can also be used, including normal-weight calcareous, siliceous and lightweight aggregates. Typically, heat is applied at a constant rate until a target temperature is reached and then the sample is maintained in a steady thermal state.

Because of its highly heterogeneous nature, concrete is more difficult to analyze under an elevated temperature than other materials. Explosive spalling has been observed for some, but not all of the tests [8,9]. Theoretical results suggest [10] that the higher susceptivity of HSC to explosive spalling can be partially attributed to the lower permeability of HSC, which limits the ability of heated moisture to escape from the concrete. This occurrence results in a buildup of pore pressure within the cement paste, the pore pressure increasing with increasing heat. This increase in vapor pressure continues until the internal stresses become large enough to cause explosive spalling of the heated concrete. Notably, explosive spalling is not always observed in replicate specimens [13-15]. In general, explosive spalling occurs in only a few of the larger groups of specimens subject to identical experimental conditions. Such erratic behavior makes it difficult to accurately predict whether or not a given HSC will fail, due to explosive spalling, when exposed to fire. 
Fiber Bragg grating (FBG) sensors are highly attractive, because of their inherent wavelength response and multiplexing capability in a distributive sensing network. In contrast to conventional strain resistance gauges, these sensors have immunity from electromagnetic interference, are small and lightweight, have high temperature and radiation tolerance and are flexible, stable and durable in harsh environments. In addition, FBG sensors are absolute and linear in response, as well as being interrupt immune and characterized by a low insertion loss; thus, they can be multiplexed in a series of arrays along a single optical fiber. Furthermore, FBG sensors have been developed for quasi-distributed or multi-point strain monitoring in both surface mounted and embedded sensing applications, providing local damage detection.

It is well known that the Bragg phase-matching condition [1] determines the Bragg wavelength, $\lambda_{B}$ of a fiber grating. The wavelength shift $\Delta \lambda_{B}$ of an FBG sensor, subjected to physical disturbance, can be expressed as

$$
\frac{\Delta \lambda B}{\lambda B}=\left(1-p_{\mathrm{e}}\right) \varepsilon+(\alpha+\xi) \Delta T,
$$

in which $p_{\mathrm{e}}, \varepsilon, \alpha, \xi$, and $\Delta T$ are the effective photoelastic constant, axial strain, thermal expansion coefficient, thermal optic coefficient and temperature shift, respectively. These coefficients generally depend on the type of optical fibers used and the wavelengths at which they are written and measured. However, in sensor applications, the wavelength shifts induced by variations of the doped materials in optical fibers can be treated as constants, as compared to those induced by structural strain, because measurements of the fractional Bragg wavelength variations, induced by the doped materials, are small.

However, since there is only one sensing parameter, i.e. wavelength shift, in the sensor application, temperature and strain cannot be measured simultaneously with a single grating. To separate the strain signal from the temperature signal, different compensation methods of temperature effects have been reported [2-7] in relevant literature. In addition, discriminating techniques have been proposed in recent years, such as using the first and second order diffraction forms to measure temperature and strain simultaneously [2], or using a chirped fiber grating, written in a tapered fiber, to fabricate a temperature-independent fiber Bragg grating strain sensor [3] Most utilize two superimposed FBGs, written at two different wavelengths, with a matrix inversion technique to decouple strain and temperature [4-7]. A new design, to distinguish the contributions of temperature and strain, is proposed in this paper. The FBG temperature sensor is shown in figure 1. This sensor, located inside a $1 \mathrm{~mm}$-diameter steel tube, silicone sealed at both ends, is used to characterize the thermal effect when the strain is applied. Note that there is adequate space to allow free displacement for temperature deformation, without any incurred stress. For reference, the FBG temperature sensor is located in the same thermal environment as the FBG strain sensor. Therefore, by subtracting the wavelength shift induced by the temperature variation from the total wavelength shift of the FBG strain sensor, we can compensate for the strain error incurred from the temperature variation.

Conventional investigation at high temperatures typically focuses on the properties of residual compressive strength,

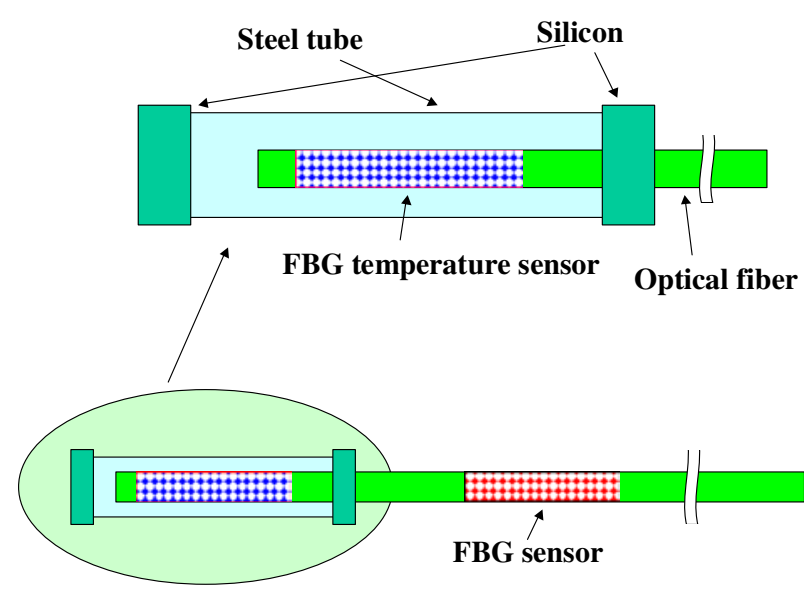

Figure 1. Schematic diagram of FBG temperature and strain sensors.

Table 1. The mixing proportions of HPC. (F: fiber, CA: coarse aggregate, FA: fine aggregate, W: water, S\&F: slag \& fly ash (7:3), C: cement, SP: superplasticizer.)

\begin{tabular}{llllllll}
\hline & \multicolumn{7}{c}{ Mix-design $\left(\mathrm{kg} \mathrm{m}^{-3}\right)$} \\
\cline { 2 - 8 } Number & CA & FA & C & S\&F & W & SP & F \\
\hline No fiber (NF) & 868 & 813 & 435 & 109 & 170 & 10.28 & 0 \\
$\begin{array}{l}\text { Polypropylene } \\
\text { fiber (PF19A) }\end{array}$ & 868 & 813 & 435 & 109 & 170 & 10.28 & 0.8 \\
$\begin{array}{l}\text { Steel fiber } \\
\text { (SFL30A) }\end{array}$ & 868 & 813 & 435 & 109 & 170 & 10.28 & 39 \\
\hline
\end{tabular}

modulus of elasticity and residual stress-strain characteristics. In this paper, properties such as thermo-strain and the response of inner temperature to elevated temperatures are monitored in real time, by the FBG sensors being embedded into a cylindrical mold and cylindrical concrete filled steel tube (CFT). In addition, the behavior of added reinforcing materials, such as steel fibers or polypropylene fibers, is investigated.

\section{Experimental setup}

To experimentally investigate the mechanical properties of HSC specimens at elevated temperatures, FBG sensors were arrayed along the central axis of the specimens. The cylindrical specimens, as depicted in figures 2 and 3, of $100 \mathrm{~mm}$ diameter and $200 \mathrm{~mm}$ height, were cured in ambient conditions after casting. The casing shell thickness of the CFT was $3 \mathrm{~mm}$. Tables 1-4 summarize the mixing proportions, mechanical properties and residual strength at elevated temperatures, as well as the probability of spalling.

As shown schematically in figures 2 and 3, to avert the lateral strain effects, both the FBG strain sensor and the FBG temperature sensor were arrayed sequentially along a single optical fiber and embedded in the direction of the central axis of the cylindrical specimens. Therefore, only the thermal strain along the central axis was measured in the cylindrical specimens. For comparison, the inner temperature of the specimens was also monitored using a thermocouple, which was embedded in the specimens, adjacent to the FBG sensor. In order to eliminate the thermal optic effect, two fiber gratings, placed in series along an optical fiber with different Bragg 

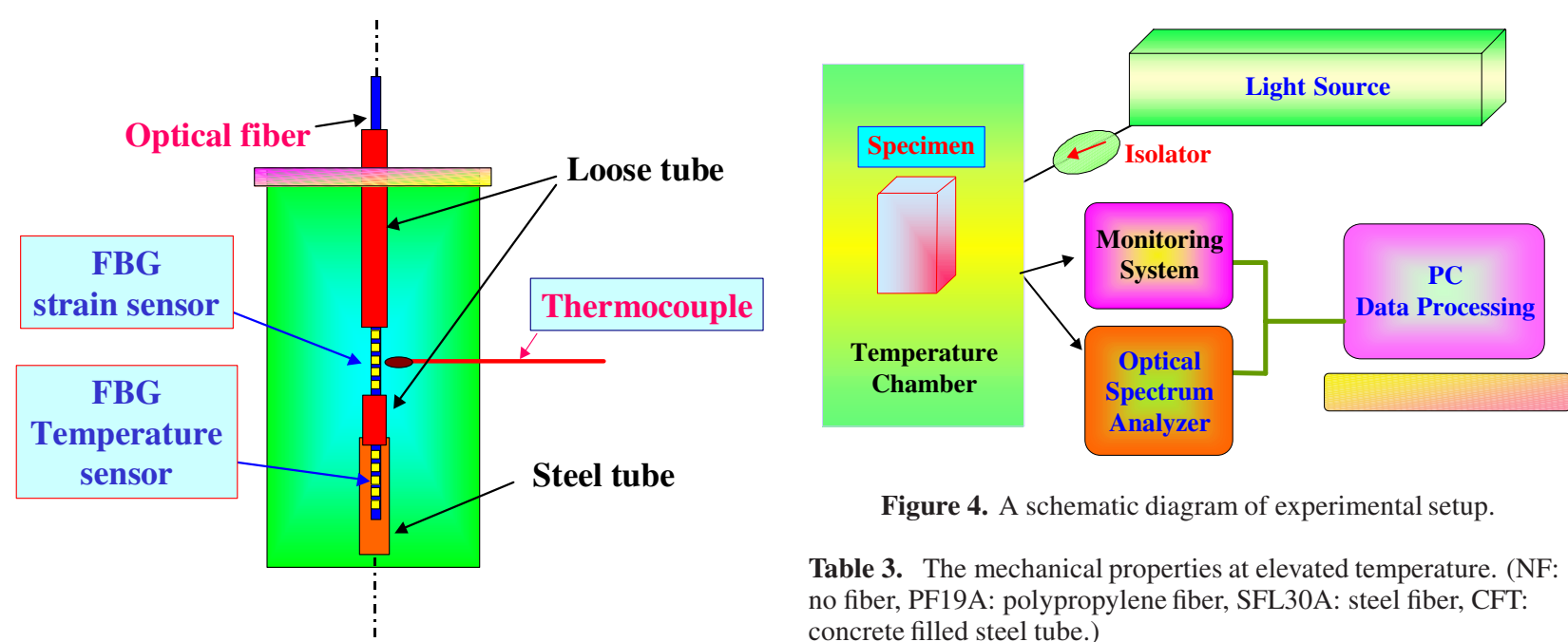

Figure 4. A schematic diagram of experimental setup.

Figure 2. An illustrated diagram of an FBG sensor in a concrete filled steel tube.

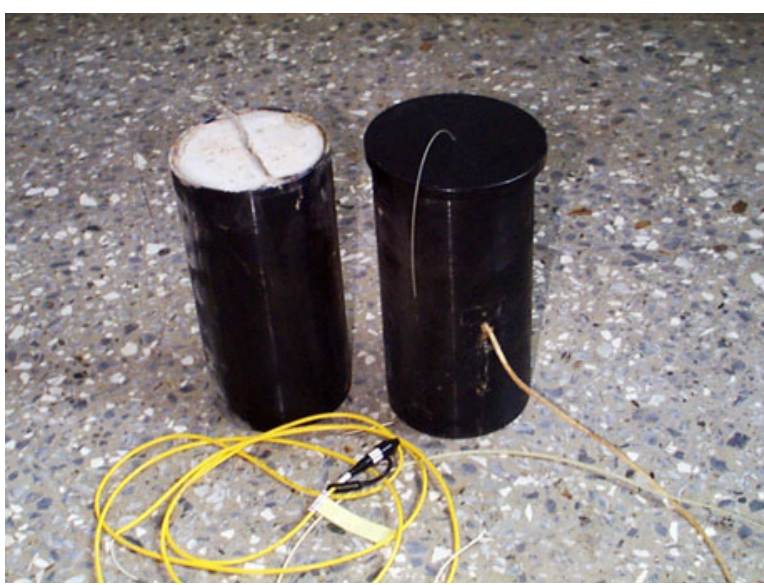

Figure 3. Schematic photograph of a concrete filled steel tube.

Table 2. The mechanical properties at room temperature. (NF: no fiber, PF19A: polypropylene fiber, SFL30A: steel fiber, CFT: concrete filled steel tube.)

\begin{tabular}{|c|c|c|c|c|c|c|}
\hline \multirow{2}{*}{$\begin{array}{l}\text { Number } \\
\text { Age and item }\end{array}$} & \multicolumn{2}{|c|}{ NF (MPa) } & \multicolumn{2}{|c|}{ PF19A (MPa) } & \multicolumn{2}{|c|}{ SFL30A (MPa) } \\
\hline & Mold & CFT & Mold & CFT & Mold & CFT \\
\hline & 47 & None & 47 & Non & 50 & Non \\
\hline 28 day & 60 & 114 & 56 & 104 & 60 & 108 \\
\hline 28 days Ec & 25892 & 19384 & 20942 & 11690 & 29321 & 15106 \\
\hline 90 days $\mathrm{fc}^{\prime}$ & 70 & 122 & 68 & 117 & 72 & 114 \\
\hline
\end{tabular}

wavelengths, were used in this research. One grating sensed the temperature and strain while the other was contained strainfree, in a loose sleeve, to measure temperature only. Hence, the strain errors caused by temperature variations can be compensated for by subtracting the wavelength shift induced by the temperature variation from the total wavelength shift obtained from the strain sensor.

Figure 4 schematically depicts the experimental setup. The heating target temperature of the experiment was $500^{\circ} \mathrm{C}$. All the specimens were heated at an elevated rate of $2.5^{\circ} \mathrm{C} \mathrm{min}-1$ in a temperature controlled chamber. The resolution and sampling rate of the FBG monitoring system,
Table 3. The mechanical properties at elevated temperature. (NF: no fiber, PF19A: polypropylene fiber, SFL30A: steel fiber, CFT: concrete filled steel tube.)

\begin{tabular}{|c|c|c|c|c|c|c|}
\hline \multirow{2}{*}{$\begin{array}{l}\text { Number } \\
\text { Age and item }\end{array}$} & \multicolumn{2}{|c|}{ NF (MPa) } & \multicolumn{2}{|c|}{ PF19A (MPa) } & \multicolumn{2}{|c|}{ SFL30A (MPa) } \\
\hline & Mold & CFT & Mold & CFT & Mold & CFT \\
\hline 7 days $\mathrm{fc}^{\prime}$ & 24 & None & 36 & None & 49 & None \\
\hline 28 days $\mathrm{fc}^{\prime}$ & 43 & - & 42 & 124 & 70 & - \\
\hline 28 days Ec & 14362 & 一 & 7072 & 7285 & 21541 & 一 \\
\hline 90 days $\mathrm{fc}^{\prime}$ & None & 一 & None & 87 & None & 一 \\
\hline
\end{tabular}

Ferret II Plus (Research International, Inc.) data processing, were set at $0.001 \mathrm{~nm}$ and $0.5 \mathrm{~s} /$ sampling, respectively. An optical spectrum analyzer (OSA, $0.07 \mathrm{~nm}$ resolution, AnritsuMS9710A) was used to monitor the signal variation at various elevated temperatures. All the FBG sensors were made of the same optical fiber and had been annealed in advance to ensure they had stabilized indices $[11,12]$. Simultaneously, the TDS302 data logger (Tokyo Sokki Kenkyujo Co., Ltd) was utilized to monitor the furnace temperature and the temperature change at the center of the specimen from the thermocouple.

\section{Simultaneous measurement of thermal strain and temperature}

\subsection{Temperature measurement}

In general, concrete is known to be able to endure heated conditions. However, high internal vapor pressure will be induced in this material, especially HPC, when it is subjected to high temperatures, possibly exploding into spall, as reported in recent investigations. Realizing temperature distribution in concrete is important. Since an FBG can subsist to about $600^{\circ} \mathrm{C}$ [12], a feasible method to measure inner temperature, using an FBG enclosed in a strain-free sleeve, was proposed. As shown in figure 4, for comparison with the thermocouple and to evaluate the practicability of the FBG temperature sensor, the specimens were heated at an elevated rate of $2.5^{\circ} \mathrm{C} \mathrm{min}^{-1}$ in a temperature-controlled chamber. Since the FBG temperature sensor was embedded near the thermocouple, as illustrated in figure 2, they were expected to have similar results. The agreement responses between FBG temperature sensor and the thermocouple, as shown in figure 5, were good. Because the two temperature sensors were placed in the same vicinity, the local particles effect of the concrete temperature can also be seen in figure 5 , 
The utilization of FBG sensors to monitor high performance concrete at elevated temperature

Table 4. Probability of concrete spalling at elevated temperature. (NF: no fiber, PF19A: polypropylene fiber, SFL30A: steel fiber, CFT: concrete filled steel tube).

\begin{tabular}{|c|c|c|c|c|c|c|}
\hline \multirow{2}{*}{$\begin{array}{l}\text { Age } \\
\text { (days) }\end{array}$} & \multicolumn{2}{|c|}{ NF } & \multicolumn{2}{|c|}{ PF19A } & \multicolumn{2}{|c|}{ SFL30A } \\
\hline & Mold (\%) & CFT (\%) & Mold (\%) & CFT (\%) & Mold (\%) & CFT(\%) \\
\hline 7 & $9 / 10=90$ & - & $0 / 10=0$ & - & $2 / 10=20$ & - \\
\hline 28 & $4 / 10=40$ & $6 / 6=100$ & $0 / 10=0$ & $0 / 6=0$ & $1 / 10=10$ & $5 / 6=83$ \\
\hline
\end{tabular}

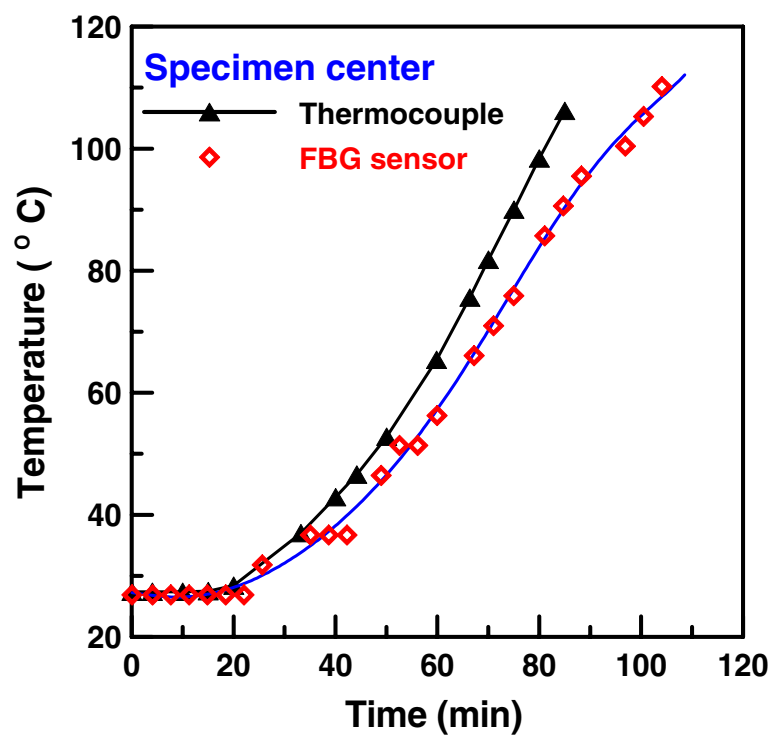

Figure 5. The comparison of thermocouple and FBG temperature sensor.

especially at high temperatures. It was evident that this FBG temperature sensor was practical for real-time monitoring of the distributed temperature of concrete when subject to fire.

\subsection{Strain measurement}

Additives to concrete, such as steel fibers or polypropylene fibers, will improve the ductility and tension mechanics of this brittle material at normal atmospheric temperatures. However, the performance of its properties when heated, such as the thermo-strain and explosive characteristics at high temperatures, needs to be further examined and clarified.

It is well known that when an FBG sensor is subjected to a non-linear deformation or split, side-lobes (figure 6) will occur [12], similar to what we see in figures 7 and 8 . In examining figures 1 and 2 , it can be seen that the FBG temperature sensor had a signal only if there was no break between the FBG temperature and strain sensors, since it was sequentially arrayed and strain-free as depicted in figure 7. But there only the signal of the FBG strain sensor from the OSA is observed, as shown in figure 8. Notably, the specimen was heated to about $250^{\circ} \mathrm{C}$ furnace temperature and $150{ }^{\circ} \mathrm{C}$ in the center of the specimen; the temperature survival capacity of the FBG sensors exceeds $600{ }^{\circ} \mathrm{C}$ [12]. It was evident that the optical fiber had been broken at some point between these two sensors. It is commonly known that in the process of heating concrete, temperature distribution and specimen gradients differ greatly, especially at high temperatures; this can induce unsymmetrical thermo-strains in the specimen. Furthermore,

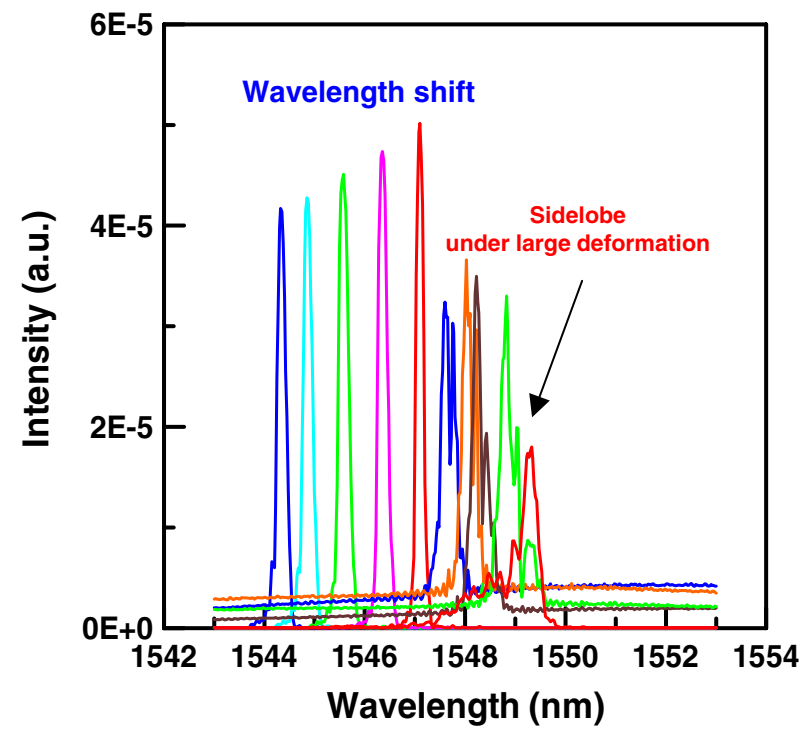

Figure 6. The FBG wavelength shift under large deformation.

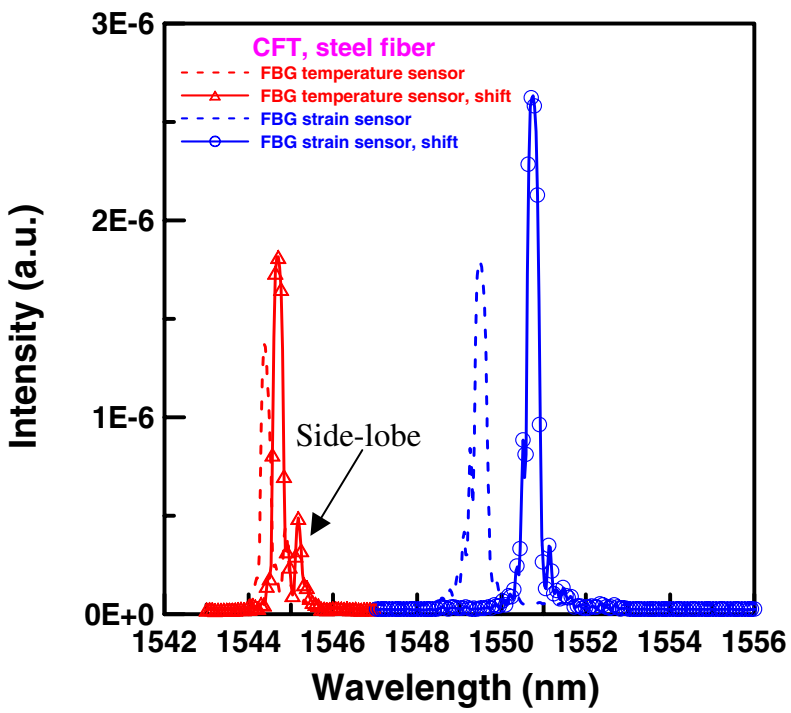

Figure 7. The wavelength shift in CFT-steel fiber.

the distinct expansion rates of paste and aggregate result in a thermal incompatibility effect, causing cracks to be initiated in the concrete, at high temperatures. After the test, the specimen was visually examined by extracting it from the confined steel tube, revealing crushed gravel. The inference of non-linear deformation, such as a crack in the concrete, which induced the split in these two FBG sensors, was then obtained. This led to a situation observed only by the spectrum of the FBG strain sensor, as shown in figure 8. 


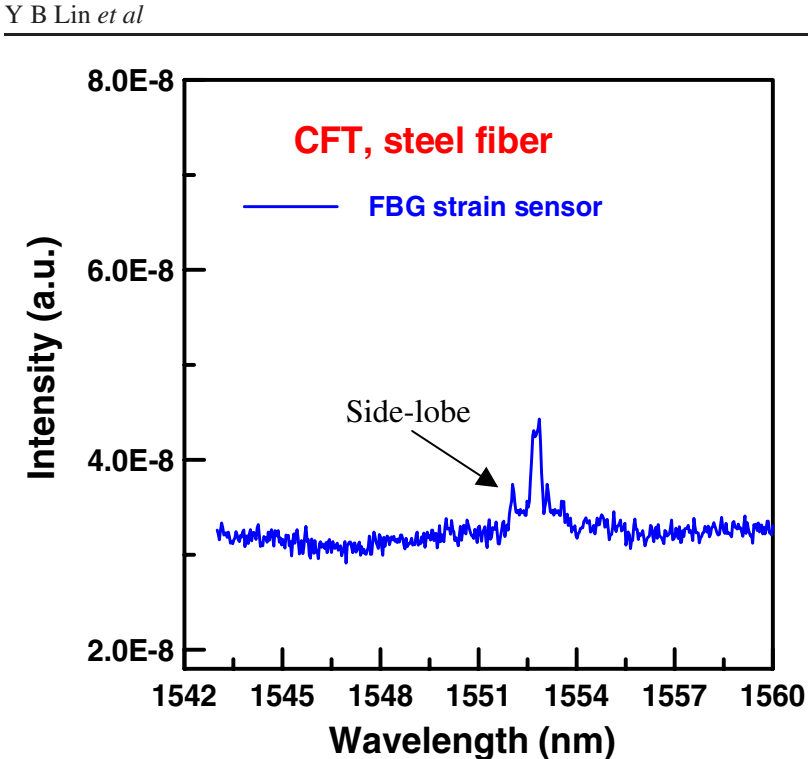

Figure 8. The FBG side-lobe in CFT-steel fiber.

To improve the toughness and tension capacity of concrete, fiber additives, such as polypropylene fiber and steel fiber were investigated; the temperature restraining characteristics of the additives were also studied. It was observed from the CFT specimen that the pulling force of the concrete material, with polypropylene fibers or steel fibers added, was less than that of plain concrete, when exposed to elevated temperatures. It is of note that all concrete cores in the CFT specimens were below the fringe of the steel tubes when cast, as shown in figure 3. This shows that concrete with additive fibers, such as polypropylene or steel, provides the concrete material of CFT with another restraint capability. The spalling probability of plain concrete CFT specimens was higher than for concrete with additive fibers, as shown in table 4.

The bridging effect of reinforcing the concrete, by the addition of fibers, prevents crack extensions and improves brittleness characteristics, such as tension strain, ductility, bending and impact effects, particularly when the HPC is confined within a steel tube, a steel spiral or tied. CFTs are used in such cases as, for example, increasing the loading capacity and stiffness of a pier or perhaps to reinforce a building for earthquake resistance. As can be seen from table 4, the additive fibers also had the capacity to increase resistance to explosive spalling. Figure 9 indicates a typical cylindrical mold, with no fiber additives, at elevated temperatures. The moisture escapes from the mold as it is heated, since concrete is a porous material, inducing shrinkage strain. As shown in figure 9, this shrinkage strain resulted in a decrease in the Bragg wavelength shift with respect to increasing temperatures, until the temperature of the furnace was at approximately $220^{\circ} \mathrm{C}$; the mold specimen then tended to expand. Meanwhile, in figure 10, the Bragg wavelength shift in the CFT with no fiber increased as the temperature increased. It is known that the moisture in concrete escapes from the mold when heated, shrinking the specimen and resulting in a compression strain, and ultimately in a shift to a shorter Bragg wavelength. Conversely, moisture cannot escape from a CFT as the steel tube surrounding the CFT and the concrete material inside have

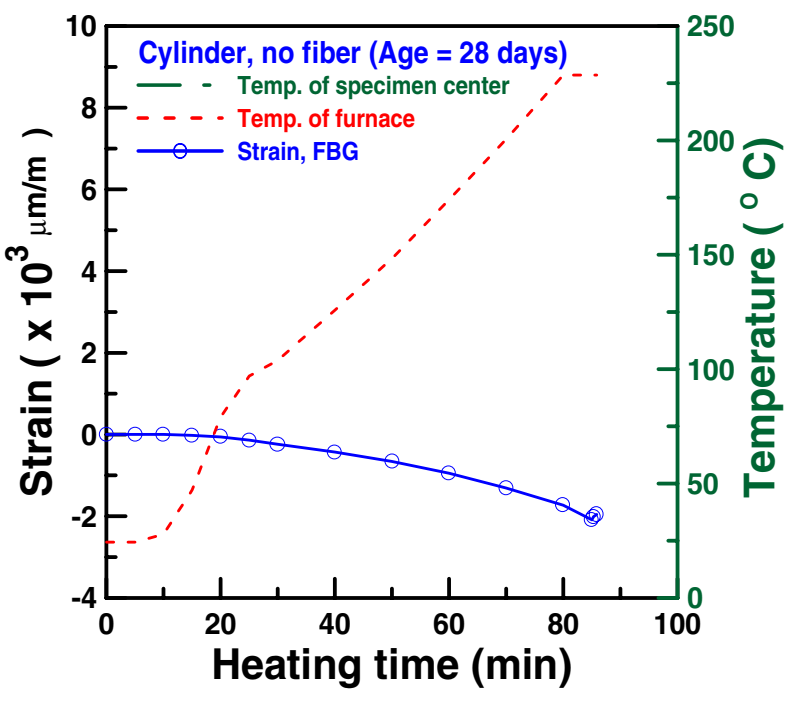

Figure 9. Strain at elevated temperature (cylinder, no fiber).

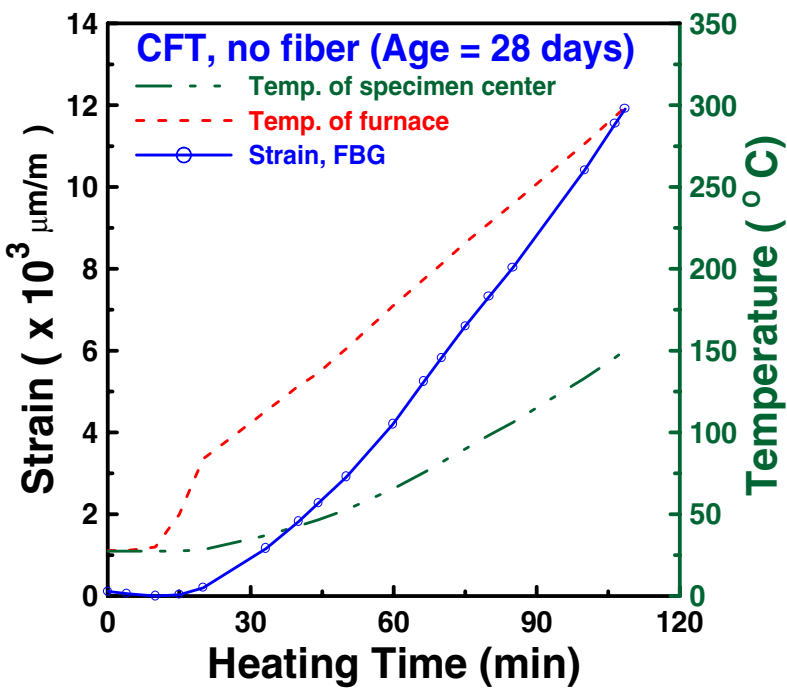

Figure 10. Strain at elevated temperature (CFT, no fiber).

different thermal expansion rates. Moreover, the tensile strain arising from the heating causes the Bragg wavelength to shift to a longer wavelength, with respect to the elevated temperature.

It has been observed that the addition of fibers, such as steel or polypropylene, to concrete material will improve its temperature restraining characteristics. Figures 11 and 12 illustrate the effects of additives such as steel fibers and polypropylene fibers. The results resemble those found in figure 10, which was concrete confined to a steel tube with no added fiber. Nevertheless, the Bragg wavelength shift at elevated temperatures, as depicted in figures 11 and 12 , is much smaller than that with no fiber in the CFT. These experimental results illustrate that the addition of steel fibers or polypropylene fibers restrained the expansion strain and improved the mechanics of the concrete. Figure 13 and table 4 reveal that the CFT with polypropylene fiber had a smaller wavelength shift than that of the CFT with steel fiber, implying that polypropylene fiber has a higher capacity to restrain the concrete from spalling than does the steel fiber. The slope 
The utilization of FBG sensors to monitor high performance concrete at elevated temperature

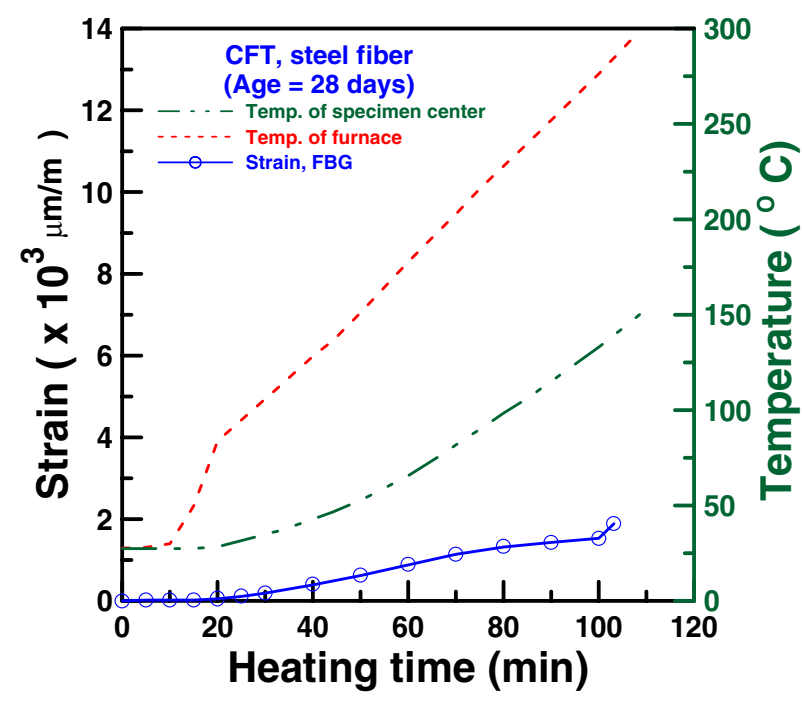

Figure 11. Strain at elevated temperature (CFT, steel fiber).

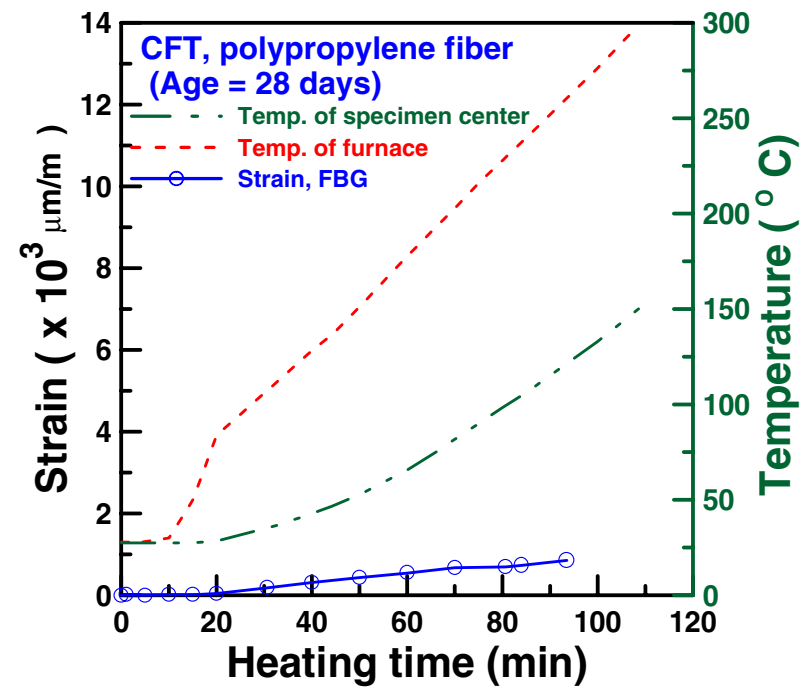

Figure 12. Strain at elevated temperature (CFT, polypropylene fiber).

relating to the concrete with steel and polypropylene fibers decreased much more than the CFT with no added fiber, as plotted in figure 14. Moreover, when comparing wavelength shifts with various heating levels, it was revealed that the grating was split when the temperature of specimen center exceeded $150^{\circ} \mathrm{C}$.

A higher shrinkage strain is known to occur at the specimen surface because the moisture, having gradually subsided, subsequently causes tensile stresses to form near the surface and compressive strains to develop at the center [16]. The experimental results indicated that the concrete heating was characterized by a steep thermal gradient when exposed to fire due to low conductivity and high heat capacity. This produced a thermal strain, particularly in the different thermal gradients of the specimen, between the steel tube and the specimen center. Consequently, micro-cracks occurred, splitting the FBG sensor. In addition, since moisture had escaped from the specimens, strength was increased as the

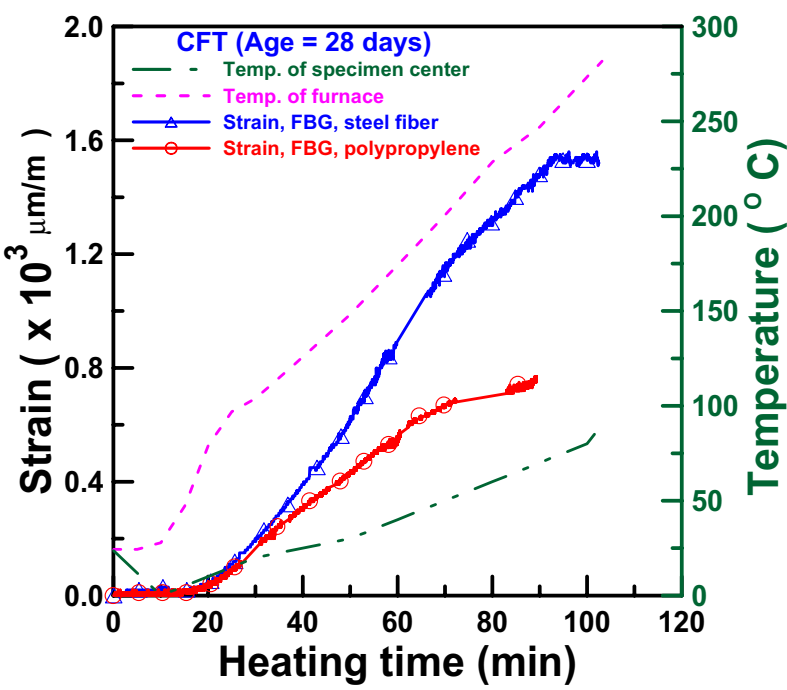

Figure 13. A comparison of steel fiber and polypropylene fiber (CFT).

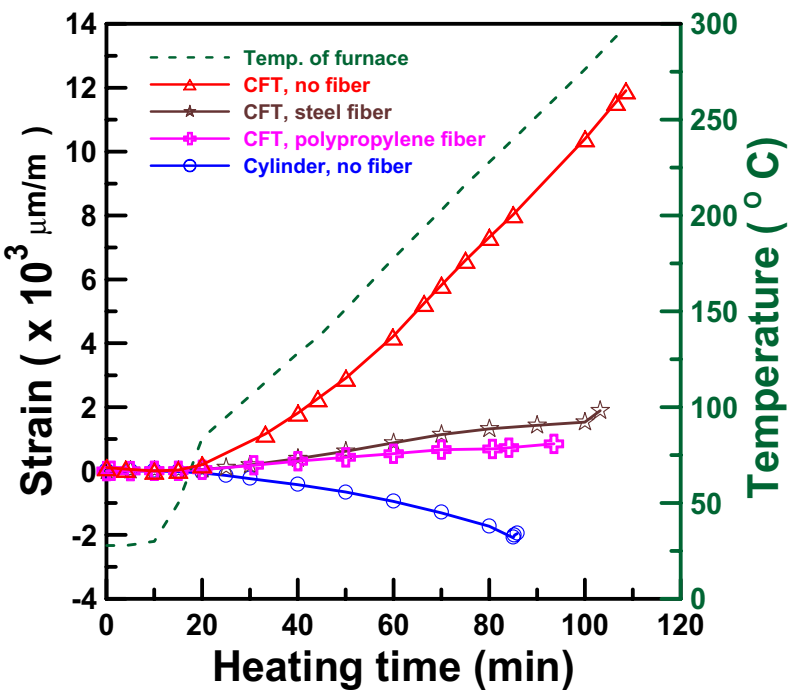

Figure 14. A comparison of strain at elevated temperature.

temperature increased and since the FBG sensors can sustain temperatures up to $600{ }^{\circ} \mathrm{C}$, the only explanation would be the initial cracking of the concrete. The stress concentration would have been generated at the fringe of the bare gratings and the jacket region of the optical fiber. However, as the temperature increased to $100^{\circ} \mathrm{C}$, the strength decreased, in contrast to room-temperature strength $[17,18]$. Because of the above reasons, the crack was induced and lengthened, thus splitting the FBG sensor.

Based on these experimental results, FBG sensors can form a dependable monitoring system for the real-time measurement of the performance of a structure subjected to fire. Indeed, this is why FBG sensors are used for the realtime monitoring of damage induced by fire. Optical fiber sensors, such as the FBG sensor, can also monitor strain and temperature simultaneously, in civil materials, when that material is subjected to elevated temperatures. 


\section{Conclusion}

This paper evaluates the properties of high performance concrete (HPC) subjected to elevated temperatures, using embedded optical fiber Bragg grating (FBG) sensors. In the experiment, the properties of the concrete, at elevated temperatures, were monitored in real time by FBG sensors embedded into cylindrical molds and cylindrical concrete filled steel tubes (CFTs). The behavior of reinforced material additions, such as steel fibers and polypropylene fibers, were also investigated.

The HPC was composed of polypropylene fibers and steel fibers as additives to the cylindrical concrete filled steel tubes (CFTs). A good agreement response between the FBG temperature sensor and a thermocouple was obtained. From the experimental results, we conclude that CFTs have completely different behavior from unconfined concrete in the center of a specimen, with furnace temperatures of $250{ }^{\circ} \mathrm{C}$, and that polypropylene fibers, potentially, have a greater capability to restrain spalling than steel fibers.

The FBG sensors failed when the temperature of the specimen center exceeded $150^{\circ} \mathrm{C}$. Since FBG sensors are viable at temperatures up to $600^{\circ} \mathrm{C}$, the only reason for this failure is the initial cracking of the concrete. The micro-cracks were generated and the stress concentrated at the fringe of the bare gratings and the jacket region of the optical fiber, splitting the FBG sensor. To resolve this problem, packaged FBG sensors will be tested in future applications.

\section{Acknowledgments}

The authors gratefully acknowledge funding during the last four years of our project, sponsored by the Ministry of Transportation and Communications, ROC. We would also like to thank Professor L A Wang, the Graduate Institute of Electro-Optical Engineering, National Taiwan University, and Chunghwa Telecom Labs, Taiwan, for their contribution to this work.

\section{References}

[1] Snyde A W and Love J D 1983 Optical Waveguide Theory (New York: Chapman and Hall)

[2] Kalli K, Brady G P, Webb D J, Jackson D A, Reekie L and Archambault J L 1995 Possible approach for the simultaneous measurement of temperature and strain via first- and second-order diffraction from Bragg grating sensors Distributed and Multiplexed Fiber Optic Sensors V; Proc. SPIE 2507 190-8
[3] Xu M G, Dong L, Reekie L, Tucknott J A and Cruz J L 1995 Temperature-independent strain sensor using a chirped Bragg grating in a tapered optical fiber Electron. Lett. 31 1085-8

[4] Miridonov S V, Shlyagin M G and Tentori-Santa-Cruz D 1999 Digital demodulation of a twin-grating fiber optic sensor Fiber Optic and Laser Sensors and Applications; Including Distributed and Multiplexed Fiber Optic Sensors VII; Proc. SPIE $354133-40$

[5] Jin X, Sirkis J S and Chung J K 1997 Optical fiber sensor for simultaneous measurement of strain and temperature Smart Structures and Materials 1997: Smart Sensing, Processing, and Instrumentation; Proc. SPIE 3042 120-7

[6] Xu M G, Archambault J L, Reekie L and Dakin J P 1994 Simultaneous measurement of strain and temperature using fibre grating sensors 10th Int. Conf. on Optical Fibre Sensors; Proc. SPIE $2360191-4$

[7] Rao Y J, Lobo Ribeiro A B, Jackson D A, Zhang L and Bennion I 1996 Simultaneously spatial-, time-, and wavelength-division multiplexed in-fiber Bragg grating sensor network Distributed and Multiplexed Fiber Optic Sensors VI; Proc. SPIE 2838 23-30

[8] Mau S T, Elwi A E and Zhou S Z 1998 Analytical study of spacing of lateral steel and column confinement J. Struct. Eng. 124 262-9

[9] Kemp A R 1998 Achievement of ductility in reinforced concrete beams Mag. Concr. Res. 50 123-32

[10] Huang Z and Platten A 1997 Nonlinear finite element analysis of planar reinforced concrete members subjected to fires ACI Struct. J. 94 272-82

[11] Liou C L, Wang L A, Shih M C and Chuang T J 1997 Characteristics of hydrogenated fiber Bragg gratings Appl. Phys. A 64 191-7

[12] Chang K C, Chern J C, Wang L A, Lin Y B and Chen H L 1998 A study of fiber Bragg grating sensors in civil structures J. Chin. Inst. Civil Hydraul. Eng. 10 467-75

[13] Bubshait A A and Tahir B M 1997 Evaluation and rehabilitation of concrete pier J. Perform. Construct. Facil. 11 113-8

[14] Sato T and Ibushi K 1988 Effect of confinement on ductile behavior of reinforced concrete in short columns Trans. Japan Concr. Inst. $10337-45$

[15] Phan L T and Carino N J 1998 Review of mechanical properties of HSC at elevated temperature J. Mater. Civil Eng. (February) 58-64

[16] Mohamad J T and Hamoush S A 1997 Effect of confinement on siliceous aggregate concrete subjected to elevated temperatures and cyclic heating ACI Mater. J. (March-April) 83-9

[17] Gray R J and Johnstont C D 1987 The influence of fibre-matrix interfacial bond strength on the mechanical properties of steel fibre reinforced mortars Int. J. Cement Compos. Lightweight Concr. 9 43-55

[18] Khan A A, Cook W D and Mitchell D 1997 Creep, shrinkage, and thermal strains in normal, medium, and high-strength concretes during hydration ACI Mater. J. (March-April) $156-63$ 